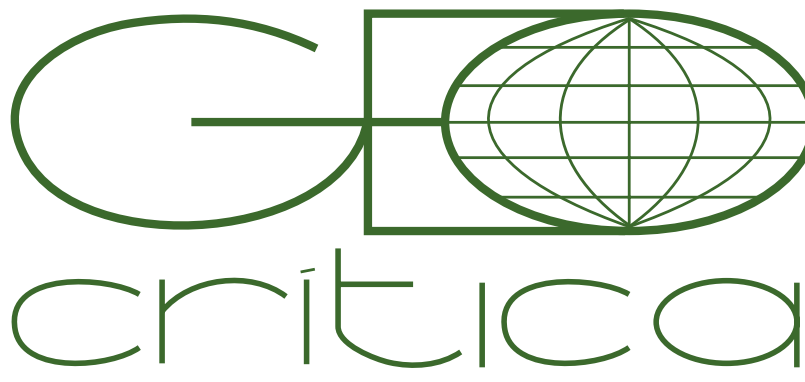

\section{Scripta Nova}

Revista Electrónica de Geografía y Ciencias Sociales Universitat de Barcelona

ISSN: $1138-97$

Vol. XXIV. Núm. 647

1 de octubre de 2020

\title{
EL TURISMO Y SU DINÁMICA EN LA BÚSQUEDA DE TIERRA Y TRABAJO BARATOS: EL CASO DE LOS CABOS, BAJA CALIFORNIA SUR, MÉXICO
}

\author{
Alejandro Escalera-Briceño \\ escalera2482@gmail.com \\ Universidad Intercultural del Estado de Puebla \\ Alejandro Palafox-Muñoz \\ alejandro.palafox.munoz@gmail.com \\ Universidad de Quintana Roo \\ Manuel Ángeles-Villa \\ manan@uabcs.mx \\ Universidad Autónoma de Baja California Sur
}

Recibido: 11 abril 2019; Devuelto para correcciones: 28 enero 2020; Aceptado: 1 mayo 2020

\begin{abstract}
El turismo y su dinámica en la búsqueda de tierra y trabajo baratos: el caso de Los Cabos, Baja California Sur, México (Resumen)

El turismo es una de las actividades más sobresalientes en la economía mundial. El turismo es un gran atractivo para las economías periféricas, que buscan enrolarse en los mecanismos desarrollistas para la generación de empleos y la captación de divisas. Desde la perspectiva de la geografía crítica, el turismo es una actividad más para producir un espacio para la acumulación de capital, y la producción del espacio turístico requiere de empaquetar de manera gratuita o barata la tierra y la fuerza de trabajo. Estos elementos de bajo costo son una constante histórica para el capital, por lo que el estudio de caso de Los Cabos, permite detallar los procesos de apropiación y capitalización para la ilimitada extracción de ganancias.
\end{abstract}

Palabras clave: Frontera mercantil del turismo, cuatro baratos, acumulación por desposesión, Los Cabos.

\section{Tourism and its dynamics in the search for cheap land and labour: the case of Los Cabos, Baja California Sur, Mexico (Abstract)}

Tourism is one of the key activities of the world economy. Tourism has become very attractive for peripheral economies that seek developmental mechanisms for the provision of jobs and the attraction of foreign investment. From a critical geography standpoint, tourism is a means for the production of space for capital accumulation that requires cheap land and labour. These low-cost elements are a historical and spatial constant, so that the case study of Los Cabos herewith presented offers an analysis of the processes of appropriation and capitalization involved in the unlimited accumulation of profit.

Keywords: Tourism Commodity Frontier, Four Cheaps, Jason Moore, Accumulation by Disposession, Los Cabos. 
El turismo es una industria que se encuentra en desarrollo desde hace varias décadas ${ }^{1}$, convirtiéndose en una actividad importante para el modo de producción capitalista. Ante ello, los anuarios estadísticos de la Organización Mundial del Turismo (OMT) son evidencia de su incremento. En 1950 el número de turistas internacionales fue de 25 millones $^{2}$; en el 2017 se registraron un total de 1,326 millones de llegadas de turistas en destinos de todo el mundo, 86 millones más en comparación con el año anterior. Este último dato representó el mayor aumento desde la crisis económica mundial de $2008^{3}$. No sorprende que la actividad favorezca al resto de sectores de la economía a través del efecto multiplicador que se manifiesta en la creación de empleos, los pagos al sector público y a la recuperación económica, entre otros factores ${ }^{4}$.

Sin embargo, los tecnócratas se interesan por las cifras antes indicadas de manera que la industria del ocio se vuelve de interés para incorporarla como política económica de Estado, por mencionar - en México - el Programa Sectorial de Turismo . $^{\text {. }}$ Con todo, desde una perspectiva crítica la industria del ocio es fundamentalmente una actividad para la acumulación del capital ${ }^{6}$, postura que arguye (en otras cosas) que la actividad turística se encuentra impulsada por las más altas instituciones internacionales del capitalismo global. En consecuencia, se promueven condiciones desiguales en las relaciones comerciales y que a su vez facilita la irrupción de las empresas multinacionales en los destinos turísticos ${ }^{7}$. Esta forma de entender al turismo se obtiene a través de un enfoque fundamentado en la economía política, uno de sus elementos clave es precisamente el intercambio desigual, cuyo resultado es cercar a las periferias para obligarlas a entregar sus recursos naturales para la maximización de beneficios externos. Desde esta óptica, la turistización de los países periféricos y "emergentes" puede interpretarse como la conformación de una frontera mercantil ${ }^{8}$, misma que consiste en una acelerada expansión de la actividad para la obtención de rentas por medio de la apropiación de materia prima (suelo, subsuelo y sobresuelo) y la explotación de la fuerza de trabajo9.

Este artículo transita en torno a la acelerada expansión del turismo en Los Cabos, Baja California Sur (México), con base precisamente en la irrupción de la frontera mercantil en ese territorio bajo el esquema de demanda y renovación de materia prima y de fuerza de trabajo. Un supuesto clave es que esta frontera ha sido promovida por el Estado mexicano por medio de sus instituciones y sus políticas, que han tenido como resultado la aparición del espacio abstracto lefebvriano ${ }^{10}$; como

\footnotetext{
1 Vera, López, Marchena y Anton 2013.

2 OMT 2016, p. 4.

3 OMT 2018, p. 4.

4 Sancho 2006.

5 Emana del Plan Nacional de Desarrollo.

6 Palafox 2013.

7 Lanfant 1980.

8 Moore 2015, p. 73.

9 Moore 2013.

10 Véase el capítulo 4 de Lefebvre 2013.
} 
una nueva dinámica dentro del tejido de la vida para la acumulación del capital. El proceso de producción social del espacio capitalista es evidente la conversión de Los Cabos en un medio de producción y al mismo tiempo en una mercancía. Esta tecnificación y mercantilización del territorio se suscita a través de una permanente acumulación por desposesión, es decir, mediante la irrupción frecuente de instalaciones turísticas. Un corolario de este dinamismo es la contradicción entre el capital y la naturaleza. En este sentido, el incesante desarrollo de las fuerzas productivas con el turismo se traduce en una forma ilimitada de acumulación, cuando la regeneración de la naturaleza es limitada. La brecha metabólica resultante de esta magna contradicción es una forma de desequilibrio procedente de la producción capitalista, en el seno de la cual la actividad turística, hoy por hoy, contribuye a la crisis ecológica ${ }^{11}$.

El objetivo principal del trabajo es emplear el concepto de frontera mercantil de Jason Moore para estudiar los procesos de turistización de Los Cabos, un Centro Turístico Integralmente Planeado (CIP) instalado por el gobierno mexicano en el estado de Baja California Sur. La conceptualización de Moore permite un acercamiento crítico a los procesos involucrados en la producción del espacio turístico en la zona, en especial dos "baratos" (empleando el lenguaje de aquel autor): la "materia prima" ( suelo y agua, por ejemplo) y la fuerza de trabajo, en aras de la acumulación de capital. Evidentemente Los Cabos no es un sujeto aislado de lo que sucede en otros destinos turísticos del mundo en cuanto a las consecuencias e impactos por el desarrollo turístico ${ }^{12}$.Tampoco lo es si se trata de la República Mexicana, pues en el país existe un total de ocho Centros Integralmente Planeados: Huatulco, Espíritu Santo, Cozumel, Riviera Nayarit, Loreto, Ixtapa, Cancún y Los Cabos, siendo este último el segundo en importancia en el país, después de Cancún ${ }^{13}$. Este hecho, amerita que se le analice como un estudio de caso de particular interés.

De acuerdo con Moore, el capitalismo neoliberal enfrenta una gran crisis, de la cual el desastre financiero de 2008/2009 y sus secuelas fueron solo botón de muestra. Hasta ahora, las crisis del capitalismo han sido resueltas mediante la introducción de novedosas tecnologías y el despliegue de otras formas de organización de la producción y el poder, incluyendo "poner a trabajar a la naturaleza de nuevas y más poderosas maneras"14. Sin embargo, "hoy es crecientemente más difícil hacer que la naturaleza proporcione su "regalos" (free gifts) de forma barata. "Estamos -afirma el autor- ante algo epocal: la descomposición de las estrategias y relaciones que han sostenido la acumulación del capital a lo largo de los pasados cinco siglos"15, fundamentada en el suministro de los Cuatro Baratos (en inglés Four Cheaps): fuerza de trabajo, alimentos, energía y materia prima ${ }^{16}$. El planteamiento de Moore es que la

11 Escalera, Palafox y Ángeles 2018.

12 Véase Cañada y Murray 2019.

13 FONATUR 2016.

14 Moore 2015, p. 2.

15 Moore 2015, p. 2.

16 Moore 2015, p. 17. 
crisis epocal a la que se hizo mención descansa sobre la imposibilidad de asegurar esa provisión a futuro. El argumento del presente trabajo es, a modo de hipótesis, que el turismo, como frontera mercantil, ha tenido el efecto de revivir las fronteras mercantiles de forma temporal, al menos dos de esos "cuatro baratos"; la materia prima (suelo y agua) y la fuerza de trabajo. A su vez, la frontera mercantil del turismo acelera el metabolismo social y al mismo tiempo genera una creciente degradación ecológica en Los Cabos.

Metodológicamente, en el trabajo se emplea un enfoque cualitativo. Se parte de una revisión bibliográfica para poner de relieve la dependencia del capitalismo de los cuatro baratos y la continua creación de fronteras mercantiles desde la historia ambiental de Moore. Esta teorización se empata con la geografía crítica de David Harvey para tomar de ahí la categoría de la acumulación por desposesión $n^{17}$ como una dinámica permanente de la reproducción del capital en el sistema-mundo, reforzada con la conceptualización de Henri Lefebvre de la producción del espacio como forma de albergar el productivismo en el turismo. Se destacan, asimismo, las argumentaciones de Bram Büscher y Robert Fletcher sobre la violencia estructural de las afectaciones ambientales y sociales que produce la industria del ocio $^{18}$. Por último, se citan resultados de un trabajo anterior de dos de los autores del presente, en el que se hizo una estimación de la tasa de explotación (al nivel sectorial) de la fuerza de trabajo en Los Cabos, empleando cifras de los Censos Económicos que en México publica el Instituto Nacional de Estadística y Geografía (INEGI). A lo largo de la argumentación, se subraya la importancia que ha tenido la nueva frontera mercantil creada por el turismo que, a semejanza de la "la destrucción creativa" del espacio turístico, ha permitido en la zona de estudio (al menos temporalmente) la renovación de dos de los cuatro baratos para continuar orbitando en la acumulación de ganancias.

\section{Generalidades de Los Cabos}

El municipio de Los Cabos se ubica en las coordenadas geográficas Norte $23^{\circ} 40^{\prime}$, al Sur $22^{\circ} 52^{\prime}$ de latitud Norte, al Este $109^{\circ} 24^{\prime}$, al Oeste $110^{\circ} 07^{\prime}$ de longitud Oeste; en el Sur del estado, colinda al norte con el municipio de La Paz, al Sur y Poniente bañada por el Océano Pacífico y al Oriente con el Golfo de California ${ }^{19}$.

La extensión territorial de Los Cabos es de 3,750.93 km2 que representa el 5.1 por ciento de la superficie estatal ${ }^{20}$. Ante esto, se convierte en el municipio con menor superficie en la península de Baja California Sur ${ }^{21}$. Los datos del INEGI del último censo estima 238,487 habitantes, por lo que representa el 37.44 por ciento del total en el estado ${ }^{22}$.

17 Harvey 2003, 2004.

18 Büscher y Fletcher 2017.

19 IMPLAN-Los Cabos 2013.

20 Gobierno del Estado de Baja California Sur 2017, p. 05.

21 IMPLAN-Los Cabos 2013.

22 INEGI 2010. 


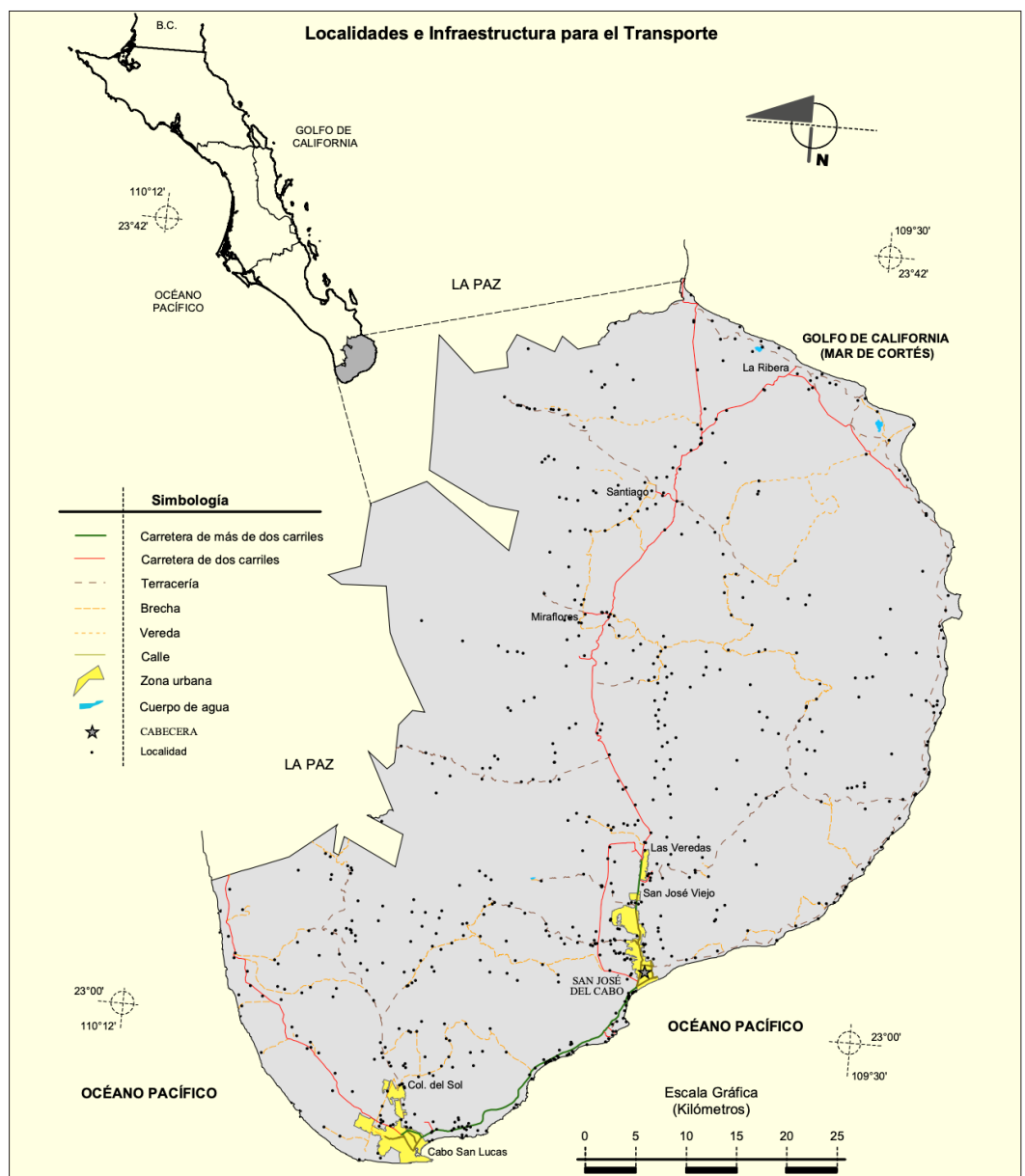

Figura 1: Ubicación de Los Cabos Fuente: |NEG|

Los Cabos forma parte de los cinco municipios del estado de Baja California Sur, entidad creada en 1980 y, en enero de 1981 entró en funciones el primer ayuntamiento, la cabecera municipal se estableció en San José del Cabo que se localiza a 190 kilómetros de la ciudad de La Paz y a 33 kilómetros de Cabo San Lucas, igualmente se debe subrayar que este municipio tiene cuatro delegaciones: a) Cabo San Lucas, b) Miraflores, c) Santiago y d) La Ribera ${ }^{23}$, además, que se encuentran establecidas 51 subdelegaciones (contando la cabecera municipal) ${ }^{24}$ cuyo funcionamiento son a través de comités de bienestar social, sus delegados son elegidos por plebiscito cada tres años ${ }^{25}$. No obstante, el municipio cuenta con 519 localidades $^{26}$ que en su mayoría son de menos de 10 mil habitantes ${ }^{27}$.

El municipio de Los Cabos tiene dos poblaciones que concentran el mayor número de habitantes y aglutinan la mayor parte de infraestructura urbana: San José del Cabo y Cabo San Lucas. Ambas localidades son ciudades medias que se conectan

23 Castorena 2012, p. 419.

24 Gobierno del Estado de Baja California Sur 2017.

25 Martínez de la Torre y Aguirre 2012.

26 Gobierno del Estado de Baja California Sur 2017, p. 05.

27 INEGI 2010. 


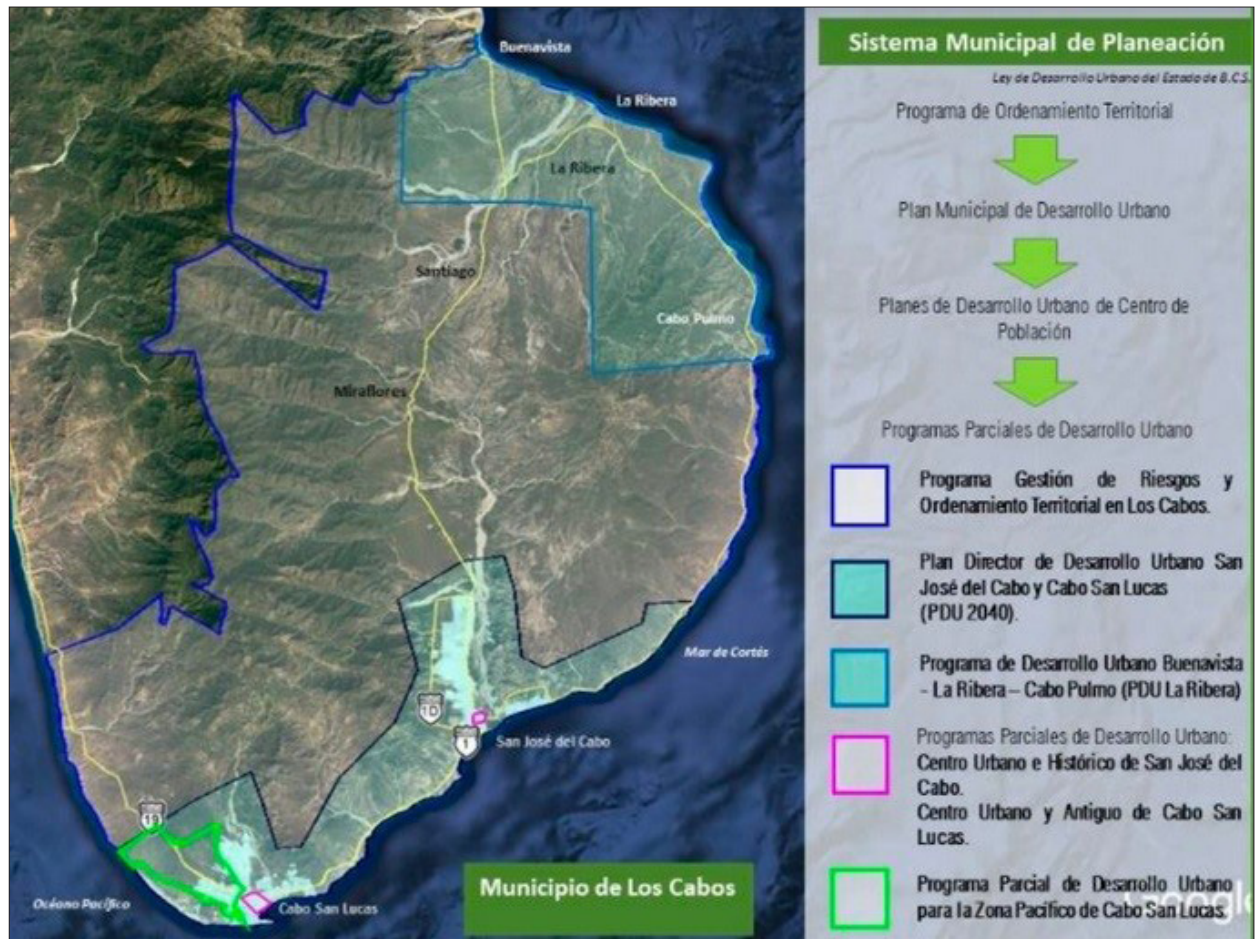

Figura 2: Ubicación del Plan Director de Desarrollo Urbano San José del Cabo y Cabo San Lucas 2040

Fuente: IMPLAN-Los Cabos

a través de una carretera con una extensión de 33 kilómetros de longitud denominada el Corredor Turístico. No sorprende, por lo tanto, que entre las dos localidades exista un flujo constante de recursos humanos y materiales ${ }^{28}$. El Plan Director de Desarrollo Urbano San José del Cabo y Cabo San Lucas 2040 define un solo centro de población que se ubica en la parte extrema sur del municipio de Los Cabos. Este centro acopla las ciudades medias de San José del Cabo y Cabo San Lucas respectivamente, el Corredor Turístico y, las localidades anexas (La Playa, Santa Anita, Santa Catarina, La Choya, Las Ánimas Bajas, Las Ánimas Altas ${ }^{29}$. La superficie de este polígono es de $54,551.49$ hectáreas $^{30}$.

San José del Cabo estadísticamente cuenta con 102,263 habitantes ${ }^{31}$, su característica de expansión es un continuo urbano que comienza con la mencionada ciudad media, extendiéndose a través de Las Veredas, San José Viejo y San Bernabé, formando una conurbación lineal ${ }^{32}$. En Cabo San Lucas, el número de habitantes es mayor que la ciudad vecina, ya que en el último censo contabilizó 146,367 personas. Respecto a su comportamiento urbano, se ha constituido una conurbación cuya tendencia es de homogeneidad en un solo asentamiento concentrado. Las colonias Lomas del Sol, Las Palmas, Cabo Bello y El Tezal forman este tipo de crecimiento.

28 Bojórquez 2014.

29 IMPLAN-Los Cabos 2013.

30 Ibíd., p. 21.

31 Ayuntamiento de Los Cabos 2015, p. 07.

32 IMPLAN-Los Cabos 2013. 


\section{La frontera mercantil con el turismo: breve andamiaje teórico}

Según Jason Moore, el capital necesita históricamente la apropiación y capitalización de cuatros elementos que son: a) la materia prima, b) la fuerza de trabajo, c) la energía y, d) los alimentos. Estos cuatro baratos (en inglés four cheaps) han sustentado la acumulación de capital desde su etapa de formación ( 1450) hasta en el actual capitalismo avanzado ${ }^{33}$. Así entonces, la frontera mercantil de la minería de plata en la época de la colonia se abastecía de estos cuatro elementos por medio de la tierra gratuita que acaparaban principalmente los españoles del Nuevo Mundo (los Andes con Potosí y el llano mexicano con Zacatecas y Guanajuato). A su vez, el trabajo esclavo que proveía el sometimiento de los pueblos originarios de América abastecía de mano de obra barata, mientras que los alimentos que se les proporcionaban a los esclavos y a trabajadores especializados procedían de otras fronteras relacionadas con la agricultura. Por último, la energía que era extraída de la madera convertida en carbón que se encontraban en los alrededores de las minas, posteriormente con el agotamiento de la madera, se implementó el método de patio el cual permitió la amalgamación con mercurio, proceso que revolucionó la minería al obtener más energía barata o gratuita al construir molinos hidráulicos o de tracción animal ${ }^{34}$. Lo antes dicho dio vida al capitalismo que al mismo tiempo se entrelazó con la frontera del azúcar, esta última reconformó las divisiones del trabajo para que no solo fuera original sino incesante ${ }^{35}$.

Debe subrayarse que el capitalismo ha continuado reformando estos cuatro baratos a través de la frontera del petróleo ${ }^{36}$ y demás actividades económicas en el capitalismo avanzado. Sin embargo, Moore augura que estos cuatro grandes están por llegar a su fin, o más bien, dejarán de ser de bajo costo, así acabando con el "capitalismo parasitario" ${ }^{37}$. Sin duda el historiador ambiental puede sospechar algo cierto, pero cabe mencionar que Rosa Luxemburgo se formuló casi la misma conjetura al precisar que el capitalismo nacional de su época entraría en una crisis de subconsumo, si éste dependiera exclusivamente de sus posibilidades internas ${ }^{38}$. Ante ello, David Harvey reformuló la acumulación originaria de Karl Marx mediante el concepto de la acumulación por desposesión, en el que enmarca nuevos mecanismos del capitalismo para continuar con la infinita acumulación del capital al explicar que la tierra agraria sirve para extender las ciudades, pero el geógrafo inglés va más allá al entender que el espacio público y los derechos de los trabajadores (las pensiones, la seguridad social) pueden ser privatizados para enrolarlos en una continua acumulación de ganancias ${ }^{39}$.

33 Moore 2015.

34 Moore 2003; Galeano 2004.

35 Moore 2003.

36 Malm 2016.

37 Moore 2013; 2016.

38 Luxemburg 1978.

39 Harvey 2003. 
De lo anterior puede ejemplificarse el caso del capital español con el proceso de internacionalización que empezó cuando el país Ibérico entró a la Unión Europea (UE). Así pues, la industria turística española, ya de gran importancia interna desde los años sesenta del siglo pasado, inició una expansión hacia el exterior (principalmente en América Latina y el Caribe) para formar nuevos espacios de acumulación (una dinámica de revitalización) y, a su vez evitar una crisis de subconsumo. Debe precisarse que en los lugares que se instala la industria del ocio promueve el deterioro laboral y ecológico, además de que crónicamente se apoya de la acumulación por desposesión para promover la especulación financiera e inmobiliaria ${ }^{40}$.

En la bibliografía crítica sobre la actividad, el turismo es considerado una industria globalizadora, cuyo propósito es insertarse en espacios para dinamizar la acumulación del capital, a saber, integrar a nuevos territorios y sectores de la población dentro del sistema-mundo, para al mismo tiempo buscar resolver las contradicciones del capitalismo para su reproducción ${ }^{41}$. Esta perspectiva permite considerar al turismo como una frontera mercantil de manera que se acopla al funcionamiento del sistema-mundo en cuanto a la extracción de los cuatro baratos, visiblemente con la materia prima (la tierra y el paisaje) y la fuerza de trabajo $\mathrm{o}^{42}$. Un primer elemento de este proceso es la producción de la naturaleza ${ }^{43}$. Neil Smith argumentó sobre la conversión de una segunda naturaleza para albergar el productivismo ${ }^{44}$; es decir, para este caso de estudio, las zonas costeras con alto valor paisajístico son apropiadas para colocar un complejo habitacional, un resort o una marina, entre otras cosas relacionadas con la actividad turística. Para el segundo elemento, dada su complejidad, podría establecerse que la apropiación de la fuerza de trabajo se da por medio de la expulsión de los trabajadores de las actividades primarias (agricultura y pesca, por ejemplo), para obligarlos a emplearse en los servicios. Esta vía promueve también el arribo de mano de obra con características específicas para ocupar los diversos puestos que ofrece la actividad y generar de esa manera un ejército industrial de desempleados, que estarían dispuestos a trabajar aceptando contratos con condiciones dolosas ${ }^{45}$. Asimismo, se identifica otra forma que se vincula con los residentes del destino, puesto que la práctica del turismo fomenta el servilismo, a saber, que la población enrolada en la división de trabajo atiende a los turistas de distintas maneras (camareros, masajistas, guías, operadores, etc.) para la reproducción de la acumulación del capital ${ }^{46}$.

No obstante, debe precisarse que la frontera mercantil del turismo se empezó a emplear en trabajos de Mowforth y Munt, quienes argumentaron sobre la mer-

40 Murray 2015.

41 Cañada y Murray 2019.

42 Los otros dos elementos se encuentran identificados con otras fronteras mercantiles que coadyuvan con la del turismo, en este sentido, la energía hallándose en la frontera del petróleo y, los alimentos con la frontera de la agricultura.

43 Proveniente de la producción del espacio en especial atención del espacio abstracto.

44 Smith 2008.

45 Cañada 2017; Rubí-González y Palafox-Muñoz 2017.

46 Büscher y Fletcher 2017. 
cantilización en un tiempo de la expansión de la industria del ocio por medio de la globalización, reforzada con el concepto del "turismo sustentable" como estrategia de crecimiento del sector ${ }^{47}$. Por su parte, Stefan Gössling hace una crítica de la "sustentabilidad" del turismo al colocar la actividad como una contradicción al decir que genera un estrés al ambiente describiendo las consecuencias ambientales globales comenzando con: a) la alteración de la tierra, b) la energía utilizada, c) el intercambio biótico y la extinción de especies, d) el intercambio y la dispersión de enfermedades y, e) los cambios en la percepción y comprensión del entorno ${ }^{48}$. Desde la ecología política es una manera de introducir el medioambiente con el propósito de mantener una relación con la explotación capitalista ${ }^{49}$; por lo que se opone a la lógica de la acumulación del capital a partir de la mercantilización de la naturaleza y el consiguiente subdesarrollo/desarrollo desigual ${ }^{50}$ (véase en la revista Ecología Política el número especial 52, dedicado a la ecología política del turismo). En general, el capitalismo es sumamente enérgico cuando se trata de intensificar las interacciones entre los seres humanos con la naturaleza ${ }^{51}$, y sus afectaciones han sido colosales, perturbando el ambiente en todas sus escalas (global, regional y local) $)^{52}$. La dinámica del metabolismo social no es en absoluto ajena a la frontera mercantil del turismo, al tratarse ambas de relaciones de poder existentes entre las diferentes clases y grupos sociales en el que las formas de vida se ponen en riesgo mediante una degradación ecológica. En el turismo esto implica transformar el suelo para la infraestructura de acceso y servicios como: alojamiento, aeropuertos, carreteras, ferrocarriles, áreas comerciales, segundas residencias, campos de golf, puertos, áreas de esquí, así como terrenos adicionales para la producción de alimentos para abastecer a hoteles y restaurantes; sitios para enterrar desechos sólidos y tierras para el tratamiento de aguas residuales. En consecuencia, se da una fuerte alteración del suelo, incluso aquel no transformado directamente por la acción humana a menudo es afectado por la fragmentación de las áreas circundantes, a lo que debe sumarse que la ciudad turística consume enormes cantidades de recursos naturales como el hídrico, pues los turistas cambian su demanda de agua frecuentemente en las zonas de escasez en razón de que usan más el recurso que en el hogar de origen, lo que aumenta su demanda mundial ${ }^{53}$.

47 Mowforth y Munt 2003.

48 Gössling 2002.

49 Durand, Figueroa y Guzmán 2011.

50 Leff 2003.

51 Metabolismo social.

52 Foster 2000.

53 Gössling 2002. 


\section{La irrupción de la frontera mercantil del turismo en Los Cabos El materialismo histórico geográfico para desvelar las dinámicas de la acumula- ción del capital}

Para mediados del siglo XIX, el territorio se configuraba por medio de pequeños asentamientos (San José, Santiago y Todos Santos); en la época de la ocupación misional, se dependía totalmente del medio físico ${ }^{54}$ para su supervivencia ${ }^{55}$. Para finales del siglo XIX, la zona estaba íntimamente ligada al extractivismo de los recursos naturales ${ }^{56}$, ello significó una inserción a la economía-mundo capitalista (espacio sometido al imperialismo económico), y sobre todo un andar estable hacia la modernización del siglo XX.

A partir del siglo XIX comenzó la conformación de un capitalismo rapaz cuyo apoyo fue a través del acaparamiento de tierras que se conjugó con el incipiente sector primario ${ }^{57}$. Para Gámez, la nueva división política en la península contribuyó a un mayor control del territorio y enmarcar en Sudcalifornia el extractivismo de los recursos mineros, forestales, pesqueros y salineros por medio de las concesiones que otorgaba el gobierno a empresas inglesas, japonesas, rusas y estadunidenses ${ }^{58}$.

En la región de Los Cabos empezaba a suscitarse un crecimiento poblacional en San José, el cual destacaba por reunir a la mitad de los habitantes, debido en gran parte por la producción y comercio de víveres con extranjeros. Esta importancia demográfica, económica, y política de la zona era en ocasiones interrumpidas por los asentamientos mineros (en San Antonio por el oro y la plata, y en Santa Rosalía por el cobre) y, sobre todo por el fortalecimiento del puerto de La Paz como capital del territorio, a pesar de ello, la economía cabeña tenía presencia relevante en San José que era el sitio de exportación importante del Territorio Sur ${ }^{59}$.

Lo antes dicho hace suponer que la región de Los Cabos estaba destinada a ser una periferia del Territorio Sudcaliforniano, ya que la sustitución de Loreto como capital tuvo un papel clave para beneficiar algunos intereses. Esta conjetura se clarifica al saber que el puerto de La Paz irrumpió como el nuevo centro económico y político en el periodo de Porfirio Díaz que benefició a una burguesía a través de la explotación de los recursos naturales ${ }^{60}$.

Para el siglo XX, especialmente en los años veinte y treinta, Los Cabos se caracterizaba por la producción agrícola, principalmente en la siembra y en el cultivo de la caña de azúcar para la producción y exportación de piloncillo, así como de tomate; además se producía en menor escala el mango, aguacate, cítricos, orégano y damiana ${ }^{61}$. Por otro lado, el poblado de Cabo San Lucas estaba íntimamente ligado a

\footnotetext{
54 una especie de simbiosis entre ser humano y la naturaleza con poca alteración del medio ambiente.

55 López 2001; Gámez 2012.

56 López 2001.

57 Gámez 2012.

58 Gámez 2012.

59 Gámez 2012.

60 López 2001.

61 López 2001.
} 
la pesca, además por empacar y comercializar el atún, ello derivó en un auge económico que provocó el crecimiento y mejoramiento de la infraestructura ya existente; sin duda la crisis global de los treinta produjo sus efectos negativos en las pequeñas comunidades de Los Cabos, sobre todo incidiendo en la depresión económica local y nuevamente en un despoblamiento por la falta de empleo ${ }^{62}$.

Iniciando la década del cincuenta comenzaron a fundarse los primeros hoteles entre San José del Cabo y Cabo San Lucas, los turistas arribaban por la vía marítima, pues el atractivo principal radicaba en la pesca deportiva ${ }^{63}$. Poco tiempo después, el canal aéreo fue otra opción para llegar al destino, entonces las aeronaves privadas comenzaron a presentarse, para lo que se construyeron entre los años cincuenta y setenta cinco aeropistas privadas, dos ubicadas en Cabo San Lucas y las restantes en San José del Cabo ${ }^{64}$. Este turismo que empezaba a desarrollarse al ritmo de un capital poco intensivo, la gente local organizaba los medios de producción y su cadena de valor, así, la escasa urbanización motivó para que fuera frecuentado por celebridades quienes arribaban en aviones privados o en yates, de esa manera fue concibiéndose como un destino turístico lujoso y exclusivo ${ }^{65}$. Posteriormente, la tecnificación de la actividad turística irrumpió en San José del Cabo por medio de una planificación que se entretejía en 1969 por el gobierno federal, quien pretendía enclavar desarrollos turísticos en varios espacios del país, conocidos más tarde como los Centros Integralmente Planeados ${ }^{66}$.

\section{La tierra barata como materia prima para emprender la producción del espacio turístico en Los Cabos}

En 1974 en Baja California Sur comenzó una serie de expropiaciones de terrenos comunales para impulsar el contrato de Fideicomiso de San José del Cabo, este proceso lo orquestó el gobierno federal por medio del Fondo Nacional de Fomento al Turismo (en adelante FONATUR) y la Comisión para la Regularización de la Tenencia de la Tierra (CORETT), dependencias gubernamentales encargadas de legalizar la tierra, así como también la urbanización y venta de lotes ${ }^{67}$. El lugar seleccionado para enclavar el nuevo complejo fue San José del Cabo, debido por su atractivo paisajístico conformado por el estero como belleza natural, al igual por el escenario físico y, especialmente por las condiciones del mercado. Como parte de esta estrategia de desarrollo, el FONATUR ejecutó diversos estudios cuyo propósito era definir los límites del predio donde se ubicaría el centro turístico, en este sentido, el fondo incluyó 1,953 hectáreas localizadas alrededor del pequeño poblado (San José del Cabo) para desarrollar la zona hotelera, los edificios para los condominios, los lotes residenciales, las playas recreativas, el campo de golf y el equipamiento urbano ${ }^{68}$.

62 Gámez 2012.

63 López-López y Sánchez-Crispín 2002.

64 Ibíd., p. 59.

65 Valiente 2015.

66 Inda y Santamaría 2015; González-Pérez et al., 2016; Montaño, Ángeles y Pérez 2019.

67 FONATUR 1982.

68 FONATUR 1982. 
La serie de expropiaciones de la tierra, Harvey lo denomina una necesidad del capitalismo avanzado para continuar con la dinámica de acumulación ${ }^{69}$. Este proceso penetró (en 1974) mediante el gobierno federal por conducto del Departamento de Asuntos Agrarios y Colonización, el cual consistió en una desposesión de 295 hectáreas que pertenecían al ejido San José del Cabo (en ese tiempo parte del municipio de La Paz), la resolución fue a favor del Banco Nacional de Obras y Servicios Públicos, S. A para que lo destinaran con fines de urbanización y desarrollo turístico $^{70}$. Claramente es una expresión del capital al incrustar nuevas políticas de acumulación ${ }^{71}$, así entonces, lo que empezó a suscitarse fue una desposesión de los bienes comunes (tierra, estero, mar, urbanización), ya que éstos antes no se mercantilizaban. Si bien, este asunto significó diversas transformaciones sobre todo la tierra (materia prima) que perdió su condición comunal o ejidal para pasar a un nuevo régimen de carácter privado. Años más tarde, la expansión del turismo y la necesidad de incorporar más espacio, esto lo menciona Lefebvre con la producción del espacio puesto que el territorio es una importante fuerza productiva ${ }^{72}$. Para ejemplificar lo antes señalado, el teórico francés lo explicó a través de las localidades francesas de Navarrenx y Lacq-Mourenx, la primera hacía referencia que no era producida por el proyecto moderno civilizatorio, es decir, un poblado que se edificaba al ritmo de las fuerzas externas (económicas, ambientales, y sociales); la segunda, enmarcada bajo una estructuración técnica y funcional de modo que fue construida en medio de la nada para responder a los flujos del capital ${ }^{73}$. Por tanto, el Centro Integralmente Planeado Los Cabos (inicialmente en San José) fue una apropiación capitalista de la pequeña ciudad que posteriormente subsumió a Cabo San Lucas.

Lo que irrumpiría en San José del Cabo por medio de la planificación del FONATUR, fue un desarrollo a mediano y largo plazo, por lo que se proyectó que en 1985 (mediano plazo) el espacio contaría con la operación de 2,400 cuartos de hotel, así como también que en el centro de la ciudad estuviera funcionando con 600 cuartos bajo el esquema de villas y condominios y, al mismo tiempo con 300 lotes residenciales; para 1990 año de la culminación de la primera fase, el fondo planeó contar con 4,620 cuartos de hotel, asimismo, la inclusión de 1,100 cuartos de villas y condominios y 550 lotes residenciales ${ }^{74}$. Por consiguiente, el objetivo del FONATUR fue desposeer y mercantilizar un espacio exclusivamente para el turismo en la cual consistió en: a) diversificar la oferta turística nacional, b) contribuir a la generación de divisas, c) penetración de nuevos segmentos de mercado turístico interno y externo, d) impulsar el crecimiento turístico general del país y e) establecer nuevos polos turísticos para promover el desarrollo regional y, en consecuencia, propiciar la acumulación del capital.

69 Harvey 2003.

70 Diario Oficial de la Federación 1974, p. 19.

71 Harvey 2003.

72 Lefebvre 2013.

73 Ibíd.

74 FONATUR 1982, p. 60. 
De acuerdo con Lefebvre, la edificación de un espacio para el capitalismo (espacio abstracto), a saber, una ciudad creada para la productividad ${ }^{75}$. Ahora, el Centro Integralmente Planeado Los Cabos evidentemente la producción de un espacio turístico en el que consistió (aún lo es) en las construcciones homogéneas (hoteles, marinas, campos de golf, segundas residencias) y, sobre todo convertir a la ciudad en medio de producción, al saber que sus componentes como la playa, el estero y demás espacios físicos son puestos en marcha para la maximización de beneficios; paralelamente, la urbanización para el ocio es percibida como una mercancía al ser organizada fundamentalmente para el consumo.

Esta arquitectura del goce en San José del Cabo tuvo ciertos criterios (ver cuadro 1), FONATUR planteó un modelo urbano para evitar el bloqueo visual de los atractivos del lugar e impuso que las fachadas fueran apegadas al lugar con la intención de crear un ambiente más agradable (en forma de oasis). El plan maestro contempló una serie de infraestructuras que le permitiría un mejor funcionamiento, movilidad y accesibilidad.

\section{Cuadro 1: Los criterios de diseño y su función}

\begin{tabular}{ll}
\hline Criterio & Función \\
\hline El estero & $\begin{array}{l}\text { Pivote principal para definir la viabilidad y las } \\
\text { diversas zonas de usos, destinos y reservas }\end{array}$ \\
La estructura vial & $\begin{array}{l}\text { Anillo para envolver la zona principal del } \\
\text { proyecto } \\
\text { Zona urbana de San José del Cabo }\end{array}$ \\
$\begin{array}{l}\text { Transversalidad para abarcar la zona turística, } \\
\text { el campo de golf y la playa }\end{array}$ \\
Zona central del poblado de San José del Cabo \\
$\begin{array}{l}\text { Atractivo arquitectónico. Al igual para definir el } \\
\text { desarrollo urbano y turístico }\end{array}$ \\
$\begin{array}{l}\text { Actividad complementaria de espacio libre y, } \\
\text { para el incremento de plusvalor de los predios } \\
\text { colindantes. Este equipamiento se refuerza con } \\
\text { el estero para el atractivo visual }\end{array}$ \\
La parte alta sur del cerro del Vigía & $\begin{array}{l}\text { Enclavar viviendas turísticas (para aprovechar } \\
\text { la vista elevada) } \\
\text { Desarrollo habitacional para los trabajadores } \\
\text { (varios núcleos autónomos) }\end{array}$ \\
\hline
\end{tabular}

Fuente: Elaboración propia con base en FONATUR 1982

La segunda etapa contemplaba el desarrollo de tres zonas que son: a) el frente de playa; b) la ampliación del campo de golf; y c) el poblado de Santa Rosa y la zona industrial; la primera zona se promovió como la más importante localizada al Este del desarrollo con superficie de 732 hectáreas, puesto que esa área se destinó para la continuación de más oferta de hospedaje, segundas residencias, y de recreación turística; en cuanto a la ampliación del campo de golf, éste se acomodaría en una superficie de 140 hectáreas de los cuales el 30 por ciento se destinó para su incre-

75 Lefebvre 2014. 
mento de sus nueve hoyos; finalmente la tercera zona involucró una superficie de aproximadamente 160 hectáreas para el crecimiento urbano ${ }^{76}$.

Cabo San Lucas localizada a 33 kilómetros de San José del Cabo ${ }^{77}$, el plan maestro del FONATUR incluyó a ese poblado para su incorporación a mediano plazo ${ }^{78}$. Al igual que la ciudad vecina, Cabo San Lucas ha sufrido cambios en el ejido especialmente entre los años sesenta y setenta, particularmente en el despojo de tierras para su dotación a la zona urbana de aproximadamente 9,626 hectáreas; posteriormente se le otorgó una ampliación con una superficie de 1,607 hectáreas; entre 1987 al 2000 la dinámica ha sido una permanente desposesión de tierras por diversas dependencias del gobierno derivado del avance de la industria del ocio ${ }^{79}$. En este sentido, Bojórquez y Ángeles detallan una serie de expropiaciones que son: a) en 1987 y 1990 por la Secretaría de Desarrollo y Ecología con 46,769,130 y 135,1 10,858 hectáreas respectivamente; b) en 1988 y 1990 por el CORETT con 31,993,729 y 62,531,027 hectáreas respectivamente; c) en 1995 la Secretaría de Comunicaciones y Transportes con 2,266,100 hectáreas; d) en 1995 por la Comisión Federal de Electricidad con 15,769,600 hectáreas; e) en 1996 y 2000 por el Gobierno del Estado de Baja California Sur con 50,020,800 y 41,208,270 hectáreas respectivamente ${ }^{80}$. Así mismo, FONATUR en 1985 emprendió un proyecto para impulsar este polo turístico con el fideicomiso Ciudad Turística Portuaria para convertirse en el megaproyecto Cabo San Lucas, éste contó con una extensión de 56 hectáreas de los cuales 34 se destinaron para el alojamiento turístico, comercial y de equipamiento, los 22 restantes al cuerpo de agua de la dársena; la materialización del proyecto concluyó en 1990 y, el fondo en esa época la promocionaría como la marina más equipada y grande de México ${ }^{81}$. A través del tiempo Cabo San Lucas se convertiría en una importante ciudad turística, sin embargo, tiene una relevante función urbanística el cual consiste como fuerza gravitacional de la industria del ocio en Baja California Sur ${ }^{82}$.

En cuanto al corredor intermedio, es un área de aproximadamente $59.51 \mathrm{~km} 2^{83}$. Este espacio antes de que el FONATUR emprendiera el Centro Integralmente Planeado, sus costas eran un atractivo existente, no obstante, dentro de su plan maestro se contempló ampliarlo en una segunda etapa con el propósito de apuntar hacia un ámbito espacial mayor ${ }^{84}$, a través del tiempo en este sitio han irrumpido complejos turísticos promoviendo la exclusividad por su punto medio que lo hace estar aparentemente retirado de las dos ciudades, en especial atención para el mercado turístico de alto poder adquisitivo ${ }^{85}$.

76 FONATUR 1982.

77 Bojórquez y Ángeles 2015.

78 FONATUR 1982.

79 Bojórquez y Ángeles 2014, p. 195.

80 Bojórquez y Ángeles 2014, p. 194.

81 López 2001, p. 199.

82 López-López y Sánchez-Crispín 2002.

83 López-López, Cukier y Sánchez-Crispín 2006, p. 306.

84 FONATUR 1982.

85 López 2001. 
Cuadro 2: Agentes que conforman el PDU 2040

\begin{tabular}{ll}
\hline Agentes & Función \\
\hline Consejo Coordinador Empresarial & $\begin{array}{l}\text { 1.- Consultoría principalmente en desarrollo } \\
\text { turístico (concentra a varias asociaciones). }\end{array}$ \\
Asociación de hoteles de Los Cabos & $\begin{array}{l}\text { 1.- Representante de los intereses hoteleros ante } \\
\text { las autoridades. } \\
2 .- \text { Cooperación entre los asociados para colaborar } \\
\text { con las autoridades de gobierno. }\end{array}$ \\
Asociación de Promotores y Desarrolladores & l- Vigilar la normatividad de los desarrollos
\end{tabular}
Turísticos Inmobiliarios de Los Cabos inmobiliarios.

Asociación Sudcaliforniana de Desarrolladores de Tiempo Compartido (ASUDESTICO)

Cámara Nacional de Comercio, Servicios Turismo de Los Cabos (CANACO)

Cámara Nacional de la Industria Restaurantera y de Alimentos Condimentos de Baja California Sur delegación Los Cobos (CANIRAC)

Colegio de Ingenieros Civiles de Baja California 1.- Apoyo empresarial. Sur sección Los Cabos

Colegio de Contadores Públicos de Baja 1.- Apoyo empresarial. California Sur delegación Los Cabos

Colegio de Arquitectos de Baja California Sur 1.- Apoyo empresarial. sección Los Cabos

Sector académico:

- Instituto Tecnológico de Estudios y opinión para la toma de decisiones de IMPLAN. Superiores de Los Cabos

- Universidad Autónoma de Baja

California Sur Extensión Los Cabos

- Centro de Investigaciones Biológicas del Noroeste

- Universidad del Golfo de California (privada)

- Universidad de Tijuana Campus Los Cabos (privada)

Fuente: elaboración propia con base en IMPLAN-Los Cabos 2013

Para López-López y Sánchez-Crispín, desde mediados del siglo XX, San José del Cabo, Cabo San Lucas y el Corredor Intermedio, se gestaba (aún lo es) un esquema de prototipo de enclave conocido como el Corredor Turístico Los Cabos (CTLC), este espacio tiene la función de articulador espacial porque enseña fuertes flujos (marítimos, aéreos y carreteros) que responden a intereses y necesidades generadas en gran parte por el capital que se encuentra fuera de México ${ }^{86}$. Así mismo, en 2010, el

86 López-López y Sánchez-Crispín 2002. 
Ayuntamiento de Los Cabos a través del Instituto Municipal de Planeación de Los Cabos (IMPLAN) diseñó el Plan Director de Desarrollo Urbano San José del Cabo y Cabo San Lucas 2040 (PDU 2040), el cual consiste en gestionar nuevos lugares de encuentro para los habitantes locales ${ }^{87}$.

Este PDU 2040 consolidó una delimitación que se conoce como: el límite de centro de población ${ }^{88}$. La junta de este plan congrega a actores sociales relevantes para la toma de decisiones (ver cuadro 2) y, con las políticas neoliberales es evidente que el capital es de primer orden. En consecuencia, la clase empresarial obtuvo gran participación política a través del Consejo Coordinador Empresarial, organismo que promovió una serie de cartas compromiso a los políticos que en ese entonces iban a ocupar cargos públicos de alcalde y gobernador (el de alcalde es ocupado por otro y el de gobernador es el actual en el cargo) para obligar la rendición de cuentas ante el consejo como práctica democrática ${ }^{89}$.

\section{El trabajo barato para el funcionamiento de la actividad turística en Los Cabos}

Las ciudades turísticas mexicanas han experimentado a partir de la tecnificación por medio de la industria del ocio el arribo de miles de personas de distintos lugares $^{90}$. Los Cabos, en especial atención el límite de centro de población (espacio donde se concentra en su mayoría los medios de producción) no se escapa de estos flujos de personas, puesto que las llegadas de turistas en el 2010 contabilizaron 1,081,743; para el año 2016 incrementó a 2,030,900 personas, en consecuencia, estas cifras posicionaron al destino en primer lugar en el pacífico mexicano ${ }^{91}$. Por otra parte, mantiene un acelerado crecimiento de población y flujo de inmigrantes provenientes de los estados de Guerrero, Sinaloa, y del Distrito Federal (ahora Ciudad de México) ${ }^{92}$, entre 1990 y 2010 el número de habitantes incrementó 443 por ciento ${ }^{93}$.

En ese aspecto, Los Cabos fue creciendo en el sector servicios, los primeros años el Centro Integralmente Planeado requirió de mano de obra especializada. En 1981 el número de empleos que generó el sector terciario fue de 832 puestos distribuidos en distintos departamentos (alimentos y bebidas; camaristas; administración, mantenimiento, etc. $)^{94}$. Evidentemente estos números a través del tiempo fueron progresando y la oferta de empleos incrementando. Lo antes referido representó una transformación estructural principalmente en los siguientes sectores: a) los servicios de alojamiento y la preparación de alimentos, b) los servicios inmobiliarios, c) la construcción, d) el comercio, e) los servicios financieros y seguros, f) los servicios de esparcimiento $\mathrm{y}, \mathrm{g}$ ) los servicios de transporte. El dinamismo del municipio por medio de esos sectores es intensivo, sin embargo, éstos fueron severamente afecta-

87 Bojórquez, Ángeles y Gámez 2019.

88 IMPLAN-Los Cabos 2013.

89 Consejo Coordinador Empresarial 2015.

90 González-Pérez et al., 2016.

91 Gobierno del Estado de Baja California 2017.

92 INEGI 2015.

93 Montaño, Pérez y De la O 2014, p. 278.

94 FONATUR 1982, p. 56. 
dos por la crisis que inició en otoño de 2008 cuyo efecto causó una fuerte reducción en los niveles de actividad y empleo, en el 2010 se registró una parcial recuperación, no obstante, el desempleo y la tasa de explotación (hacia la fuerza de trabajo) se mantienen en cifras muy altas ${ }^{95}$.

Sin duda, en el espacio turístico en Los Cabos es evidente el aumento en los ingresos para los agentes relacionados con la industria del ocio, es decir, las compañías hoteleras, los especuladores, el sector financiero y las empresas inmobiliarias. Por otro lado, también se registra un incremento en el empleo en los servicios de apoyo al turismo de muy baja calificación y remuneración. Lo anterior se puede sostener por medio de un ejército industrial de reserva que es abastecido por migrantes de otros estados del país. De acuerdo con Moore, para lograr más plusvalor se debe introducir los cuatro baratos a la ley de valor, en este sentido, la fuerza de trabajo de bajo costo puesto que hay un gran número de seres humanos o cuerpos subalternos tales como: pobres, mujeres, personas de color, y demás indeseados por el sistema capitalista ${ }^{96}$. Por tanto, el tipo de desarrollo que experimenta Los Cabos se manifiesta por medio de insuficiente infraestructura para la población local, altos niveles de subempleo, marginación e informalidad ${ }^{97}$; más bien, experimentando un crecimiento urbano y el aumento de la segregación social como parte de los efectos del desarrollo turístico ${ }^{98}$.

La experiencia de las dos principales ciudades turísticas en Baja California Sur enseña tres apariencias distintas; la primera, la ciudad para los turistas que pueden pagar hasta 1,500 dólares de estancia por noche; la segunda, para el residente extranjero y nacional que pagan departamentos en exclusivas zonas residenciales o en lugares estratégicos; y la tercera, las zonas miseria donde habitan los empleados del sector terciario. En un estudio reciente, en un asentamiento miseria ubicado a 10 minutos del centro de Cabo San Lucas que lleva por nombre El Caribe, el trabajo reveló la existencia de 1,640 casas donde más de 9 mil personas viven en situación de hacinamiento ${ }^{99}$. Ahora bien, esta tercera apariencia podría correlacionarse con los datos del Consejo Nacional de la Política de Desarrollo Social (CONEVAL) de Los Cabos (de 2015), el cual estimó a 75,328 en pobreza moderada y 9,243 en pobreza extrema ${ }^{100}$; esta estadística supone un alto grado de desarrollo desigual, al compararse con las grandes inversiones inmobiliarias para el turismo y las necesidades de las zonas marginadas ${ }^{101}$. A pesar de ello, el éxito del destino turístico como modelo de acumulación del capital está en función de los altos montos de ganancias y el valor agregado que se genera, el cual se ubicó en 69 por ciento, es decir, de cada peso de producto, 69 centavos lo absorbieron los capitalistas (ver cuadro 3), ante esto,

95 Martínez, Ángeles y Gámez 2013.

96 Moore 2015.

97 Martínez, Ángeles y Gámez 2013.

98 González-Pérez et al., 2016.

99 Martínez, Ángeles y Gámez 2013, p. 10.

100 CONEVAL 2015.

101 Montaño, Pérez y De la O 2014. 
debe subrayarse el bajísimo nivel de salario que se pagó en el sector construcción puesto que reflejó el hecho de que casi el 89 por ciento del valor agregado fluyó a los capitalistas $^{102}$.

Cuadro 3: Los Cabos, ganancias / Valor Agregado por sector, 2013

\begin{tabular}{lr}
\hline Sector & Porcentaje (\%) \\
\hline Agricultura, ganadería, caza y pesca & 75,74 \\
Minería & 78,65 \\
Electricidad, gas y agua & 78,48 \\
Construcción & 88,46 \\
Industrias manufactureras & 68,81 \\
Comercio al por mayor & 70,77 \\
Comercio al por menor & 83,48 \\
Transportes, correos y almacenamiento & 47,78 \\
Información en medios masivos & 81,10 \\
Servicios financieros y seguros & 57,45 \\
Servicios inmobiliarios & 71,44 \\
Servicios profesionales & 47,60 \\
Servicios de apoyo a negocios & $\mathbf{6 9 , 1 9}$ \\
Servicios educativos & 30,62 \\
Servicios de salud y asistencia social & 60,84 \\
Servicios de esparcimiento & 65,51 \\
\hline Mervicios de alojamiento y alimentos & 81,11 \\
\hline
\end{tabular}

Fuente: Elaboración propia con base en INEGI, 2014

Lo antes dicho pone de manifiesto la enorme rentabilidad que tiene la edificación y venta de segundas residencias en el municipio, pero también, la realidad del obrero de la construcción al contar con poca capacidad para su reproducción social (vivienda, alimentos, vestimenta, esparcimiento y recreación). Esta experiencia no es un caso particular sino una contradicción que se replica en otros destinos como en 102 Ángeles, Gámez y Escalera 2017. 
Bávaro-Punta Cana (República Dominicana) y Varadero (Cuba) donde sus impactos se materializan bajo la forma de urbanismo precario ${ }^{103}$. Si bien estos trabajadores radican en zonas urbanas y periféricas basadas en la informalidad (considerados cinturones de miseria), por ejemplo, como el de la colonia El Caribe en Los Cabos. En aquel destino turístico, en la actualidad, el urbanismo precario se observa en las zonas de arroyos donde son clasificadas de alto riesgo para establecer casas-habitación, por tanto, las colonias El Caribe, Invasión Caribe, Real Unidad en Cabo San Lucas; Arroyo Santa Rosa, y La Ballena en San José de Cabo son necesarias para la reproducción de la acumulación del capital. Ello está íntimamente ligado por una gama de factores como: a) la enorme concentración de riqueza que se observa en el municipio, el estado, el país y el mundo; b) la informalidad; c) las reformas laborales instituidas desde los noventa y consolidadas en 2012; y d) la explotación laboral.

En su práctica, la explotación de la fuerza de trabajo en Los Cabos fue de 288.28 por ciento, a saber, por cada peso de salario al trabajador, redituó 2.88 pesos en ganancias para el capitalista, los sectores relacionados con la industria del ocio detallaron una alta tasa de explotación, en ese aspecto, la construcción fue el que obtuvo mayor peso con 766.25 por ciento ${ }^{104}$ (ver cuadro 4). La colonia El Caribe aglutina trabajadores vinculados al sector terciario y sus salarios mensuales giran alrededor de los 5 mil a 10 mil pesos mensuales, y otros sobreviven con menos de 5 mil pesos ${ }^{105}$.

Cuadro 4: Tasa de explotación de los principales sectores del turismo

\begin{tabular}{lrr}
\hline Sector & Tasa de explotación & Porcentaje \% \\
\hline Construcción & 7.66 & 766.25 \\
Comercio al por mayor & 2.42 & 242.09 \\
Comercio al por menor & 5.06 & 505.51 \\
Transportes & 0.92 & 91.50 \\
Servicios inmobiliarios & 2.50 & 250.16 \\
Servicios de esparcimiento & 4.29 & 429.30 \\
Servicios de alojamiento y & 5.06 & 505.72 \\
alimentos & & $\mathbf{2 8 8 . 2 8}$ \\
\hline Media & $\mathbf{2 . 8 8}$ & \\
\hline
\end{tabular}

Fuente: Elaboración propia con base en datos del INEGI

En Los Cabos es notable el nivel de superexplotación, pese a que, la industria del ocio la oculta a través de la creación de espacios de trabajo. Es importante apuntar que la investigación que se realizó en la colonia El Caribe, las encuestas revelaron que los habitantes en ese asentamiento se encuentran contentos de vivir ahí, pese a que no hay servicios de salud, drenaje y agua potable constante. La población re-

103 González-Pérez et al., 2016.

104 Ángeles, Gámez y Escalera 2017.

105 Martínez, Ángeles y Gámez 2013, p. 12. 
sidente considera que son vulnerables a enfermedades respiratorias y estomacales, aunque su mayor peligro sea el riesgo de vivir en el paso de un arroyo ${ }^{106}$.

Desde una perspectiva crítica, es el propio capitalismo quien reproduce los asentamientos marginales, por medio de una política neoliberal restablece patrones de acumulación e instituye nuevas relaciones de producción enmarcadas en la precarización ${ }^{107}$. Sin embargo, la brecha entre asentamientos (para el turismo y residencias de los obreros) juega un papel importante, ya que la urbanización precaria o los cinturones de miseria son un facilitador de fuerza de trabajo para poner en marcha el complejo proceso de producción del espacio turístico. Las implicaciones de este fenómeno es la expansión y prolongación de las colonias marginadas, más aún, el surgimiento de nuevas. Esto se relaciona con el incremento de infraestructura turística, el cual tiene un impacto migratorio entre siete y nueve personas por la construcción de un cuarto de hotel ${ }^{108}$. Ante esto, es claro que el sostenimiento del desarrollo del turismo como negocio es a través del aumento del margen de control de los empresarios (hoteleros, restauranteros, constructoras) sobre la plusvalía y las formas de extracción (contrataciones por temporadas, salarios por debajo de la ley porque se compensan con propinas, entre otras cosas), lo que posibilita una mejor adaptabilidad del capital. La materialidad de esta relación social de producción se refleja en un amplio sector de asalariados en condiciones inestables viviendo en zonas deprimidas e informales.

El capitalismo transforma y reorganiza el mundo para el beneficio de la acumulación de ganancias ${ }^{109}$. De acuerdo con Moore, alude de que lo antes dicho es un movimiento histórico dentro del desarrollo del capitalismo (tejido de la vida) ${ }^{110}$. Gran parte de esta co-producción de naturaleza barata bajo la forma de fuerza de trabajo se encuentra representada en una división internacional de trabajo en la cual la tasa de explotación se comporta de distintas formas y reflejan un muy alto nivel de superexplotación. La explicación a esta situación es de que el capital se apropia de la naturaleza (la fuerza de trabajo) pagando poco o incluso nada por ella, por lo que el incremento de las fuerzas productivas es a través de este proceso para generar más plusvalor ${ }^{111}$. Ante esta situación, se trata pues, de un modelo económico basado en la explotación ilimitada.

\section{La frontera mercantil del turismo en Los Cabos como catalizador de la degradación ecológica a través de su metabolismo social}

El turismo suele verse como una representación del capitalismo ${ }^{112}$; por tanto, la acumulación del capital esconde los impactos negativos de la industria del ocio. Para

106 Martínez, Ángeles y Gámez 2013.

107 Ruiz 2016.

108 Graciano 2018, p. 180.

109 Harvey 2003.

110 Moore 2015.

111 Moore 2015.

112 Fletcher 2011. 
Büscher y Fletcher la actividad turística genera procesos de mercantilización por lo que desencadena diversas formas de violencia estructural ${ }^{113}$. De lo antes dicho se desprende un tipo de violencia que se asocia a las afectaciones del medioambiente ${ }^{114}$ y generación de desechos ${ }^{115}$. Entonces, el turismo bajo la concepción de estrategia de acumulación de beneficios se encuentra distante de ser un representante ecológico $^{116}$. Si bien, la economía política del turismo hace referencia en especial atención que las fuentes sistémicas de poder reflejan la constitución de la competencia por los recursos y la manipulación de la escasez, en virtud de ello, convierten a las personas, los lugares e historias en objetos para el consumo turístico ${ }^{117}$. En efecto, la relación capitalista en cuanto al orden metabólico (la asociación entre la sociedad y la naturaleza) es la causante de un desequilibrio (brecha metabólica) ${ }^{118}$; principalmente debido a procesos de tecnificación de la naturaleza en la cual esta última es incorporada a un circuito económico ${ }^{119}$.

En Los Cabos, estos desequilibrios empezaron a manifestarse cuando se produjo una intensificación del suelo, subsuelo y sobresuelo al enclavar el Centro Integralmente Planeado, consecuentemente la degradación del medioambiente se volvió una constante. Lo anterior se puede evidenciar ( sin ser la única) a través del estrés del suelo al establecer una representación de la naturaleza (paisaje ficticio). En este sentido, el estero San José ha sufrido afectaciones considerables por consecuencia del desarrollo urbano y turístico (amenaza alta y media), especialmente sobre el cuerpo de agua dulce, la vegetación acuática, los matorrales, las especies, y la playa $\operatorname{arenosa}^{120}$. El megaproyecto Puerto Los Cabos (a un costado de San José del Cabo), el Grupo Questro (empresa encargada de la obra) modificó sustancialmente el paisaje del estero a pesar de que fuera declarada en 1994 Área Natural Protegida (ANP). Los reclamos de ambientalistas, principalmente por Greenpeace, puso en evidencia la perturbación del ambiente debido al vertido de lodos producto de los desechos de dragado y vaciado de aguas residuales hacia el mar, asimismo, este organismo internacional advirtió que el efecto de ese hecho sería (actualmente los es) la inevitable reducción de agua dulce en la región ${ }^{121}$.

Otra problemática en Los Cabos es la escasez de agua. En virtud de ello, la industria turística acapara gran parte del recurso hídrico para el riego de los campos de golf, las piscinas, las áreas verdes, entre otras locaciones ${ }^{122}$. Como se sabe, este polo turístico se encuentra en una zona árida y con problemas de agua para satisfacer al tejido urbano y turístico, sin embargo, la industria del ocio es la que se privilegia

113 Büscher y Fletcher 2017.

114 Gössling 2002.

115 Büscher y Fletcher 2017.

116 Fletcher 2016.

117 Bianchi 2011.

118 Foster 2000.

119 Smith 2008.

120 Pronatura Noroeste 2010.

121 Greenpeace 2007.

122 Valiente 2015. 
del preciado recurso porque gran parte de su oferta hotelera representa el 90 por ciento de cuartos de hotel de cinco y cuatro estrellas, sin embargo, éstos tienen mayores servicios a disposición para los turistas, por tanto un alto consumo hídrico ${ }^{123}$. De acuerdo a estándares internacionales, un cuarto de hotel consume en promedio $1.5 \mathrm{~m} 3$ por día que equivalen al uso de 4.3 personas, así pues, Los Cabos oferta 15 mil cuartos de hotel de modo que los turistas utilizan $23 \mathrm{mil} \mathrm{m} 3$ diariamente que bien podría corresponderle a 63 mil personas, ahora, un campo de golf de 18 hoyos requiere en promedio $2,300 \mathrm{~m} 3$ por día que semejan a la utilización doméstica de 8 mil personas, en este sentido, el destino turístico cuenta con 11, cuyo consumo de agua podría abastecer a 88 mil personas, es importante señalar que no se toma en consideración los lagos artificiales por lo cual la contabilidad hídrica se cuadruplicaría $^{124}$.

Ante la problemática del suministro hídrico en la que se encuentra la urbanización de Los Cabos, los tecnócratas pretenden arreglarlo por medio del mercado, en ese caso la estrategia del gobierno local es implementar plantas de desalinización para potabilizar el agua de mar, se precisa que al presente existe una instalada desde el 2006 con inversión de 300 millones de pesos bajo el esquema público-privado, ésta se encuentra concesionada por 20 años a la empresa PROMAQUA filial del consorcio español Obrascon Huarte Lain (OHL) con la intención de abastecer aproximadamente a 25 colonias populares que podría asimilarse a 85 mil personas al día ${ }^{125}$. Aunque, la Comisión Nacional del Agua (CONAGUA) reconoció en el destino turístico 72 concesiones para desalinización, la institución pública desconoce su operación, funcionamiento y, capacidad; debe precisarse que, con certeza algunas concesiones enseñan su poder económico, por mencionar, el caso del Chileno Bay cuyo permiso supera los $10.4 \mathrm{Mm} 3$ anuales, es decir, lo suficiente para suministrar el recurso hídrico a una población de 58 mil habitantes al día ${ }^{126}$. Empero, la población que sufre por el agua no dimensiona la problemática ya que la industria del ocio es la que oferta los puestos de trabajo, a pesar de ello, estas personas con sus propios recursos económicos aprovisionan el vital líquido a través de camiones cisterna (pipas) que llevan el recurso a las comunidades marginadas, aun así, insuficiente ${ }^{127}$.

En otro orden de ideas, en Los Cabos se presencia una problemática en relación con el tema energético. En este sentido, un estudio reciente reveló que la actividad turística de Los Cabos está gatillando en gran medida los consumos de energía en Baja California Sur, por lo que su uso final fue de 313,470 megavatio por hora (MW/h), ahora, en comparación con La Paz, fue de 164,591 mw/h, obviamente, el destino turístico consumió más del doble de la energía; no obstante, para complejizar las cosas, el puerto de La Paz es el punto de desembarque de los flujos energéticos contenidos en los alimentos, así como también, es el espacio donde se genera la

123 Graciano 2018, p. 167.

124 Ibíd.

125 Valiente 2015; Graciano 2018.

126 Graciano 2018, p. 139.

127 Valiente 2015. 
energía eléctrica, ambos elementos fluyen hacia Los Cabos para sostener a la industria del ocio, lo antes dicho trae efectos nocivos a la sociedad paceña y, sus implicaciones se relacionan con la salud y los efectos ambientales que ya se hacen presentes con la calidad del aire ${ }^{128}$.

\section{Conclusiones}

La frontera mercantil del turismo es una manera de apropiarse de al menos dos de los cuatro baratos, es decir la materia prima (la tierra) y la fuerza de trabajo. En Los Cabos dicha frontera irrumpió a mediados de los setentas con el propósito de restaurar la acumulación del capital, a saber, la organización del espacio a cargo del capital por medio de la producción del espacio (urbanización turística y constante privatización de tierras) en la cual las rentas y su distribución es para unos cuantos. Lo antes dicho se logra a través de la acumulación por desposesión, que se materializa mediante el cercamiento de los bienes comunes (zonas costeras, el estero, el espacio público, entre otros) como mecanismo para llevarlos al mercado, en este caso el turístico. Por tanto, la producción del espacio turístico alivia la sobreacumulación de capital, proporcionando una salida, si bien efímera, de la crisis. Dada esta salida, se da posteriormente, un aumento de las inversiones con la ayuda de la deuda, por lo que su efecto es la reproducción de más crisis.

Ahora bien, la frontera mercantil del turismo muestra que la acumulación del capital impacta con gran intensidad en el tejido de la vida, incluso vinculándose con otras fronteras (petróleo, producción de alimentos, entre otros) para darle un nuevo sentido a los cuatro baratos sin que éstos lleguen a su fin (y, por supuesto, seguir orbitando en el modo de producción capitalista a fin de no desaparecer). En Los Cabos esta dinámica ha generado una violencia estructural vinculada a la degradación ambiental, que dentro de la literatura ecológica heterodoxa se denomina: brecha metabólica. En virtud de ello, la actividad turística y su interacción metabólica (relación sociedad y naturaleza) generan beneficios especialmente para los capitalistas, distanciándose de la perspectiva co-evolutiva (para todos los seres humanos y mejoramiento de la naturaleza). Ante esto, es claro que la frontera del turismo no es un guardián ecológico, sino una contradicción entre el capital y la naturaleza, por lo cual la regeneración de la naturaleza es lenta ante la ilimitada acumulación de ganancias, además de los conflictos ecológico-distributivos ocasionados por la apropiación de los bienes comunes.

\section{Bibliografía}

ÁNGELES VILLA, Manuel, GÁMEZ VÁZQUEZ, Alba y ESCALERA BRICEÑO, Alejandro. Ciclos de crecimiento económico y tasa de plusvalor en economías subnacionales turistizadas: los casos de Baja California Sur y Quintana Roo. Anais Brasileiros de Estudos Turísticos-ABET, 2017, vol. 7, núm. 3, p. 42-50.

128 De la Peña 2017, p. 181. 
AYUNTAMIENTO DE LOS CABOS. Plan de desarrollo municipal Los Cabos 2015-2018. México: H. XII Ayuntamiento Los Cabos, B.C.S, 2015, 151 p.

BIANCHI, Raoul. Tourism, capitalism and marxist political economy. En MOSEDALE, Jan. Political economy of tourism a critical perspective. London: Routledge, 2011, p. 15-38.

BOJÓRQUEZ LUQUE, Jesús. Evolución y planeación urbana en la ciudad turística de Cabo San Lucas, Baja California Sur (México). Pasos, 2014, vol. 12, núm. 2, p. 341-356.

BOJÓRQUEZ LUQUE, Jesus y ÁNGELES VILLA, Manuel. Expansión turística y acumulación por desposesión: el caso de Cabo San Lucas, Baja California Sur (México). Cuadernos de Geografía, 2014, vol. 23, núm 2, p. 179-202.

BOJÓRQUEZ LUQUE, Jesus, ÁNGELES VILLA, Manuel y GÁMEZ VÁZQUEZ, Alba. El derecho a la ciudad y rescate del espacio público en zonas urbanas turistizadas. Una reflexión para Los Cabos, Baja California Sur (México). Aposta. Revista de Ciencias Sociales, 2019, núm. 80, p. 109-128.

BÜSCHER, Bram y FLETCHER, Robert. Destrutive creation: capital accumulation and the structural violence of tourism. Journal of Susteinable Tourism, 2017, vol. 25, núm, 5, p. 651-667.

CAÑADA, Ernest y MURRAY, Ivan. (eds.). Turistificación global. Perspectivas criticas en turismo, Barcelona: Icaria Editorial, 2019, 480 p.

CAÑADA, Ernest y MURRAY, Ivan. Introducción: perspectivas críticas en turismo. En: CAÑADA, Ernest y MURRAY, Ivan. Turistificación global. Perspectivas críticas en turismo, Barcelona: Icaria Editorial, 2019, p. 7-34.

CAÑADA, Ernest. Un turismo sostenido por la precariedad laboral. Papeles de Relaciones Ecosociales y Cambio Global, 2017, núm, 140, p. 65-73.

CASTORENA DAVIS, Lorella. Turismo, ruralidad y urbanización en el municipio de Los Cabos: un reto para el desarrollo. En: GANSTER, Paul, ARIZPE, Oscar e IVANOVA, Antonina. Los Cabos. Prospectiva de un paraíso natural y turístico, Estados Unidos de América: San Diego State University Press - Institute for Regional Studies of the Californias, 2012, p. 417-438.

CONEVAL. Medición de la pobreza, Baja California Sur, 2010-2015. México: CONEVAL, 2015.

CONSEJO COORDINADOR EMPRESARIAL. Compromisos con candidatos a gobernador del estado, 2015-2021, vamos por diez [en línea]: <http://defiendelasierra.org/wpcontent/uploads/2015/06/Compromisos-Carlos-Mendoza-Davis-Vamos-porDiez-CCA-Jun-2015.pdf> [Consulta: 29 de marzo de 2018].

DE LA PEÑA BARRON, Adolfo. Metabolismo social, energía y cambio climático en el estado de Baja California Sur. Tesis de doctorado, La Paz: Universidad Autónoma de Baja California Sur, 2017,232 p. 
DIARIO OFICIALDE LA FEDERACIÓN.Departamento de asuntos agrarios y colonización, México: DOF, 1974.

DURAND, Leticia, FIGUEROA, Fernanda y GÚZMAN, Mauricio. La ecología política en México ¿Dónde estamos y para dónde vamos? Estudios Sociales, 201 1, vol. 19, núm. 37, p. 282-307.

FONATUR. Destinos turísticos de FONATUR [en línea]: <https://www.gob.mx/fonatur/ acciones-y-programas/destinos-fonatur> [Consulta: 2 de marzo de 2020]

FONATUR. San José del Cabo. Un desarrollo turístico de cara al siglo XXI. México, D.F: FONATUR, 1982, $95 \mathrm{p}$.

FOSTER, John. La ecología de Marx. Materialismo y naturaleza. Barcelona: Ediciones de Intervanción Cultural / El Viejo Topo, 2000, 448 p.

FLETCHER, Robert. Tours caníbales puesto al día: la ecología política del turismo, Ecología Política, 2016, núm. 52, p. 26-34.

FLETCHER, Robert. Sustaining tourism, sustaining capitalism? The tourism industry's role in global capitalist expansion, Tourism Geographies, 201 1, vol. 13, núm. 3, p. 443-461.

GALEANO, Eduardo. Las venas abiertas de América Latina. México, D.F: Siglo Veintiuno Editores, 2004, $270 \mathrm{p}$.

GÁMEZ VÁZQUEZ, Alba. Los Cabos: una semblanza histórica. En: GANSTER, Paul, ARIZPE, Oscar e IVANOVA, Antonina. Los Cabos. Prospectiva de un paraíso natural y turístico, Estados Unidos de América: San Diego State University Press - Institute for Regional Studies of the Californias, 2012, p. 213-230.

GOBIERNO DEL ESTADO DE BAJA CALIFORNIA SUR. Baja California Sur información estratégica. La Paz: Gobierno del Estado de Baja California Sur, 2017, 44 p.

GONZÁLEZ-PÉREZ, Jesús, REMOND-ROA, Ricardo, RULLAN-SALAMANCA, Onofre Y VIVES-MIRÓ, Sònia. Urban growth and dual tourist city in the Caribbean. Urbanization in the hinterland of the tourist destinations of Varedero (Cuba) and Bávaro-Punta Cana (Dominican Republic), Habitat International, 2016, vol. 58, p. 59-74.

GRACIANO, Juan Carlos. Uso, manejo y apropiación del agua en destinos turísticos. El caso del municipio de Los Cabos, Baja California Sur. Tesis de doctorado, La Paz: Universidad Autónoma de Baja California Sur, 2018, 258 p.

GREENPEACE. Greenpeace demanda al ayuntamiento de Los Cabos y a constructora [en línea]: <http://www.greenpeace.org/mexico/es/Noticias/2007/Mayo/ greenpeace-demanda-al-ayuntami/> [Consulta: 15 de abril de 2018]

GÖSSLING, Stefan. Global environmental consequences of tourism. Global Environmental Change, 2002, vol. 12, núm. 4, p. 283-302.

HARVEY, David. El "nuevo" imperialismo: acumulación por desposesión. Socialist Register, 2004, núm. 40, p. 100-129. 
HARVEY, David. The New Imperialism. New York: Oxford University Press, 2003, 253 p.

IMPLAN-LOS CABOS. Segunda actualización del Plan Director de Desarrollo Urbano San José del Cabo-Cabo San Lucas B.C.S. 2040. Baja California Sur: Gobierno del Estado de Baja California Sur-SEDATU, 2013, 294 p.

INDA, Marco Tulio y SANTAMARÍA GÓMEZ, Arturo. Los Centros Integralmente Planeados (CIP'S) en México. Revista Latino-americana de Turismologia, 2015, vol. 1, núm. 1, p. 36-56.

INEGI. Principales resultados de la encuesta intercensal 2015: Estados Unidos Mexicanos. Aguascalientes: INEGI, 2015, 122 p.

INEGI. Censo de población y vivienda 2010, Aguascalientes: INEGI, 2010, 125 p.

INEGI. División territorial del estado de Baja California de 1810 a 1995. Aguascalientes: INEGI, 1997, 99 p.

LANFANT, Marie-Francoise. Introducción: el turismo en el proceso de internacionalización. Revista Internacional de Ciencias Sociales, 1980, vol. 32, núm. 1, p. 14-45.

LEFEBVRE, Henri. Toward an architecture of enjoyment. Minneapolis: University of Minnesota Press, 2014, 190 p.

LEFEBVRE, Henri. La producción del espacio. Madrid: Capitán Swing, S.L, 2013, 451 p.

LEFF, Enrique. Ecologia y capital. Racionalidad ambiental, democracia participativa y desarrollo sustentable. México, D.F.: Siglo XXI Editores, 2003, 437 p.

LÓPEZ LÓPEZ, Álvaro. Análisis de la organización territorial del turismo de playa en México, 1970-1996. El caso de Los Cabos, B.C.S. Tesis de doctorado, Ciudad Universitaria, México: Universidad Nacional Autónoma de México, 2001, 390 p.

LÓPEZ LÓPEZ, Álvaro y SÁNCHEZ CRISPÍN, Álvaro. Canales espaciales de articulación en el corredor turístico Los Cabos, Baja California Sur, México. Cuadernos de Turismo, 2002, núm. 9, p. 53-66.

LÓPEZ LÓPEZ, Álvaro, CUKIER, Judith y SÁNCHEZ CRISPÍN, Álvaro. Segregation of tourist space in Los Cabos, Mexico. Tourism Geographies, 2006, vol. 8, núm. 4, p. 359-379.

LUXEMBURG, Rosa. La acumulación del capital. España: Grijalbo, 1978, 454 p.

MALM, Andreas. Fossil capital: the rise of steam power and the roots of global warming. Londres: Verso, 2016, 496 p.

MARTÍNEZ, Hilda, ÁNGELES VILLA, Manuel y GÁMEZ VÁZQUEZ, Alba. Bienestar socioeconómico y percepción de la calidad de vida en destinos turísticos: el caso de la colonia El Caribe, Cabo San Lucas, Baja California Sur (México). Revista de Investigación en Turismo y Desarrollo Local, 2013, vol. 6, núm. 15, p. 1-16. 
MARTÍNEZ DE LA TORRE, Antonio y AGUIRRE OSUNA, Lizzeth. Administración pública y gobierno en el municipio de Los Cabos. En: GANSTER, Paul, ARIZPE, Oscar e IVANOVA, Antonina. Los Cabos. Prospectiva de un paraíso natural y turístico, Estados Unidos de América: San Diego State University Press - Institute for Regional Studies of the Californias, 2012, p. 329-354.

MONTAÑO, Angélica, ÁNGELES, Manuel y PÉREZ, Juan. Tourist destinations with asymmetrical local development: the "Integrally Planned Tourist Centres" of Los Cabos and Loreto, Baja California Sur (Mexico). International Journal of Sustainable Development and Planning, 2019, vol. 14, núm. 1, p. 44-61.

MONTAÑO ARMENDÁRIZ, Angélica, PÉREZ CONCHA, Juan y DE LA O BURROLA, Verónica. Reposicionamiento para destinos turísticos consolidados: el caso de Los Cabos, México. Cuadernos de Turismo, 2014, núm. 33, p. 271-295.

MOORE, Jason. El fin de la naturaleza barata: o cómo aprendí a dejar de preocuparme por "el" medioambiente y amar la crisis del capitalismo. Relaciones Internacionales, 2016, núm. 33, p. 143-174.

MOORE, Jason. Capitalism in the web of life: ecology and the accumulation of capital. New York: Verso, 2015, 336 p.

MOORE, Jason. El auge de la ecología-mundo capitalista (II). Las fronteras mercantiles en el auge y decadencia de la apropiación maxima. Laberinto, 2013, núm. 39, p. 21-29.

MOORE, Jason. Nature and the transition from feudalism to capitalism. Review Fernand Braudel Center, 2003, vol. 26, núm. 2, p. 409-433.

MOWFORTH, Martin y MUNT, Ian. Tourism and sustainability: development and new tourism in the Third World. USA y Canada: Routledge, 2003, 330, p.

MURRAY MAS, Ivan. Capitalismo y turismo en España. Del "milagro económico" a la "gran crisis". Barcelona: Alba Sud Editorial, 2015, 424, p.

OMT. Panorama OMT del turismo internacional Edición 2018. Madrid: OMT, 2018, 19 p.

OMT. Panorama OMT del turismo internacional. Madrid: OMT, 2016, 20 p.

PALAFOX MUÑOZ, Alejandro. El turismo como eje de acumulación. Nómadas, 2013, Edición Especial America Latina, p. 161-174.

PRONATURA NOROESTE. Plan de conservación del Estero de San José del Cabo, B.C.S., México. La Paz: Pronatura Noroeste, 2010, 54 p.

RUBÍ GONZÁLEZ, Felipe y PALAFOX MUÑOZ, Alejandro. El turismo como catalizador de la pobreza. Trabajo turístico y precariedad en Cozumel, México. Barcelona: Alba Sud Editorial, 2017, $84 \mathrm{p}$.

RUIZ BRUZZONE, Felipe. Superexplotación de la fuerza de trabajo en América Latina: consideraciones teóricas. Revista Izquierdas, 2016, núm. 30, p. 236-257.

SANCHO, Amparo. Introducción al turismo. Madrid: OMT, 2006, 394 p. 
SMITH, Neil. Uneven development, capital, and the production of space. USA: The University of Georgia Press, 2008, 344 p.

VALIENTE, Carmina. La producción del espacio turístico-inmobiliario en Sudcalifornia y la apropiación de los bienes comunes. Tesis de maestría, La Paz: Universidad Autónoma de Baja California Sur, 2015, 201 p.

VERA, Fernando; LÓPEZ PALOMEQUE, Francisco; MARCHENA, Manuel y ANTON, Salvador. Análisis territorial del turismo y planificación de destinos turísticos. Valencia: Tirant Humanidades. Colección Crónica, 2013, 473, p.

ZAFIROVSKI, Milan. Measuring and making sense of labor exploitation in contemporary society: a comparative analysis. Review of Radical Political Economics, 2003, vol. 35, núm. 4, p. 462-484

(c) Copyright: Alejandro Escalera-Briceño, Alejandro Palafox-Muñoz \& Manuel Ángeles-Villa, 2020

(C) Copyright: Scripta Nova, 2020.

Ficha bibliográfica:

ESCALERA-BRICEÑO, Alejandro; PALAFOX-MUÑOZ, Alejandro; ÁNGELES-VILLA, Manuel. El turismo y su dinámica en la búsqueda de tierra y trabajo baratos: el caso de Los Cabos, Baja California Sur, México. Scripta Nova. Revista Electrónica de Geografía y Ciencias Sociales. Barcelona: Universidad de Barcelona, 1 de octubre de 2020, vol. XXIV, ${ }^{\circ}$ 647. [ISSN: 1138-9788] 